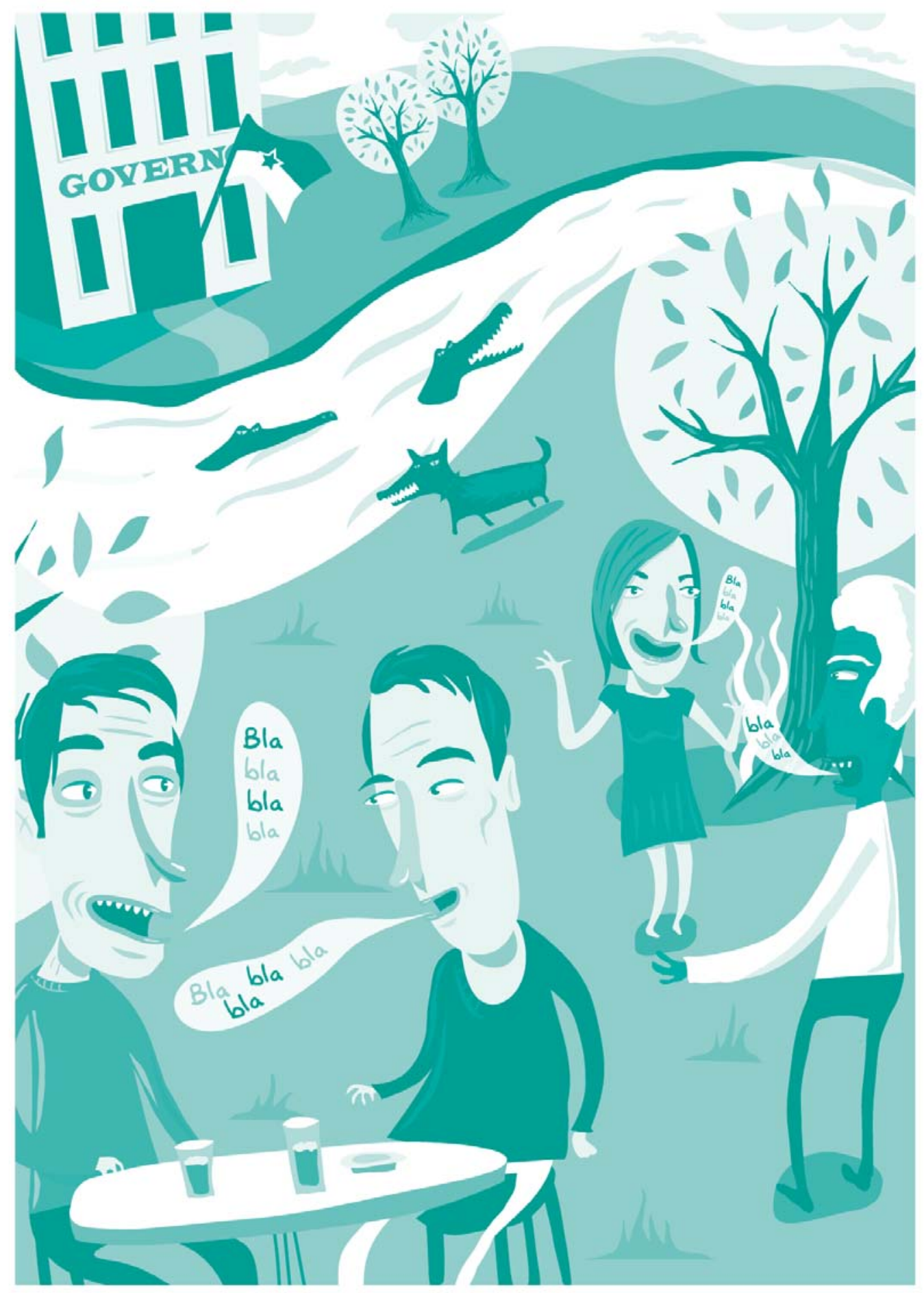




\section{Comunicação Política Comunicação Pública}

Heloiza Helena Gomes de Matos

- Livre-docente da Universidade de São Paulo (USP)

- Pós-doutora pela Université Stendhal Grenoble, Stendhal, França

- Doutora e Mestre em Ciências da Comunicação pela USP

- Graduada em Jornalismo pela Universidade Federal de Juiz de Fora (UFJF)

- Professora titular da Faculdade de Comunicação Social Casper Líbero

- Publicou 14 artigos em periódicos especializados e 23 trabalhos em anais de eventos. Possui 11 capítulos de livros e 6 livros publicados

- Orientou 15 dissertações de mestrado e 5 teses de doutorado

- Atua na área de Comunicação, com ênfase em Mídia, Eleições e Democracia

-heloizamatos@uol.com.br 


\section{Resumo}

O artigo analisa a Comunicação Pública como uma vertente da Comunicação Política, buscando discutir o conceito por sua natureza multipolar, comunicativa, política e de mercado. Embora a centralidade da mídia seja considerada determinante, o artigo também indica como as transformações na tecnologia e no mercado contribuíram para a emergência de novas formas de interação política.

PALAVRAS-CHAVE: COMUNICAÇÃo PÚblica - COMUNiCAÇÃo POLÍtica - TECNOLOGia E MERCADO

\section{Abstract}

The article analyzes the Public Communication as part of the Political Communication. It aims to discuss this concept through its multipolar, communicative, political, and market nature. Although the centrality of the media is considered determinative, this paper also discusses the transformations in the technology and in the market, and the new forms of political interaction.

KEYWORDS: PUBLIC COMMUNICATION - POLITICAL COMMUNICATION - TECHNOLOGY AND MARKET

\section{Resumen}

El artículo analiza la Comunicación Pública como una vertiente de la Comunicación Política, buscando discutir el concepto a través de su naturaleza multipolar, comunicacional, política y de mercado. A pesar de considerarse determinante la centralidad de los medios, el artículo también apunta como las transformaciones en la tecnología y en el mercado contribuyeron para la aparición de nuevas formas de interacción política.

PALABRAS CLAVES: COMUNICACIÓN PÚBLICA - COMUNICACIÓN POLÍTICA - TECNOLOGía Y MERCADO 


\begin{abstract}
análise da Comunicação Pública pretendida neste estudo acompanha a natuA reza do conceito e os marcos da sua evolução histórica como modelo teórico1 instrumental do sistema político para mediar interações comunicativas entre o Estado e a sociedade. Embora considere a centralidade da mídia, o artigo discute em que medida as transformações na tecnologia e no mercado contribuíram para a emergência de redes de interação, nas quais a Comunicação Pública está implicada.
\end{abstract}

Há algum tempo, os estudiosos de comunicação têm reiteradamente usado o conceito de Comunicação Pública sem muita clareza em seu significado. Em artigo sobre a comunicação no legislativo, Matos (1999) tentou apontar tendências da Comunicação Pública na França e nos Estados Unidos com base em outras vertentes, ou seja, em propaganda e em marketing político. Ainda naquele artigo, a autora chamava a atenção para a organização da sociedade civil após a ditadura militar e a partir do processo de redemocratização no Brasil. Vislumbrou encontrar, além da tendência dominante do marketing como linguagem da Comunicação Política, a presença de grupos sociais com vários níveis de organização e capazes de encontrar espaços e mídia para a manifestação de diferentes vozes.

À época de redação do artigo, tentava-se decretar novamente o fim da comunicação governamental centrada e controlada pelos atores do sistema político e apresentar, ainda de modo difuso, os atores sociais emergentes na esfera pública com capacidade para debater e formular propostas em face dos apelos das campanhas institucionais. A esta nova modalidade de comunicação chamamos "Comunicação Pública".

Vale assinalar que a atualização dos estudos de Comunicação Política privilegia, de forma evidente, as mensagens políticas, as políticas de comunicação governamental, as campanhas eleitorais e as mídias envolvidas neste processo (em especial a televisão e, mais tarde, a Internet). O conceito de "Comunicação Pública" incorporou-se ao vocabulário de comunicação, apoiado talvez pelas referências dominantes à comunicação governamental, ao marketing político e ao e-governo.

Diante disto, o desafio que se impõe neste artigo é buscar na Comunicação Política (como estudo de técnicas de persuasão e como o referencial teórico e metodológico) ajuda para a compreensão do conceito de Comunicação Pública - invocado ora como utopia, ora como conceito renovado de comunicação governamental ou, ainda, como o próximo passo nas relações comunicativas entre o Estado (não o governo) e a sociedade. 


\section{Revisão conceitual}

Aqui propomos identificar as diferentes modalidades de tratamento que se tem dado ao conceito da Comunicação Pública. Ou seja, uma visão geral a partir das relações entre governo e sociedade: uma abordagem da Comunicação Pública como serviço público, tomando por base as experiências decorrentes da regulação das mídias de massa pelo Estado; a emergência do mercado; e um terceiro aspecto relacionado à visão normativa da Comunicação Pública.

O Glossário de Comunicação Pública destaca o seguinte como referência para os estudos neste campo:

"Matos e Brandão fazem uma releitura dos conceitos e apresentam uma versão que congrega os principais pontos, que são: a participação do Estado, do Governo, da sociedade e do Terceiro Setor, a localização na esfera pública e a fundamentação no interesse público. Matos define Comunicação Pública como 'processo de comunicação instaurado em uma esfera pública que engloba Estado, governo e sociedade, um espaço de debate, negociação e tomada de decisões relativas à vida pública do país'. A autora relaciona Comunicação Pública com democracia e cidadania e pensa a Comunicação Pública 'como um campo de negociação pública, onde medidas de interesse coletivo são debatidas e encontram uma decisão democraticamente legitima'. Na mesma direção, Brandão define Comunicação Pública como 'o processo de comunicação que se instaura na esfera pública entre o Estado, o Governo e a Sociedade e que se propõe a ser um espaço privilegiado de negociação entre os interesses das diversas instâncias de poder constitutivas da vida pública no pais"”. (DUARTE e VERAS, 2006, p. 26)

Uma análise do uso da expressão "Comunicação Pública" desde o início do século XX mostra que o conceito esteve relacionado com a comunicação estatal e a implantação da radiodifusão, e, mais tarde, da televisão pública. A imprensa tradicional se desenvolveu regulada pelas forças políticas, culturais e de mercado, ao passo que os meios eletrônicos necessitavam ser autorizados e regulados por concessão pública. Por esta autorização, o Estado "concede a uma empresa, por tempo limitado, o direito de utilizar uma determinada faixa, mediante o compromisso de que será usada em benefício público” (DINES, 2005).

No entanto, embora haja diferenças entre a origem dos recursos financeiros (privados) e a origem da concessão e regulamentação (estatais), as finalidades que orientam o funcionamento da mídia deveriam ser guiadas pela satisfação do interesse público.

No Brasil, a implantação da radiodifusão (anos 20) consagrou a expressão "Comunicação Pública”, entendida como comunicação estatal. Isto é, o termo era utilizado em contraste à comunicação do setor privado. 
Com o fim do governo militar, os segmentos sociais interessados se organizaram para discutir políticas públicas compatíveis com a tarefa de democratização da comunicação.

Com a promulgação da Constituição Federal de 1988, foram instituídos três sistemas complementares de serviços de radiodifusão: o privado, o público e o estatal (art. 23 da CF/ 88). Neste sentido, Comunicação Pública é a comunicação realizada por meio da radiodifusão pública, nos moldes de sistema público apresentado por Tomaz Jr., que explica que

“por 'sistema público' entendem-se não as instituições do 'setor público', que se confundem com o estatal, mas sim os espaços e organizações geridos de forma 'pública': coletiva, transparente, em observância de princípios democráticos de participação e de controle social. Obviamente, o tipo de conteúdos, a natureza da organização, entre outros elementos, como a propriedade, também compõe o mosaico de itens que serve para denotar o caráter público aqui referido". (TOMAZ JR. apud DUARTE, 2006, p. 27)

No entanto, o art. 23, embora defina o sentido da Comunicação Pública do ponto de vista legal e normativo, não leva em conta as transformações das tecnologias da informação que já estavam em vigor nos meios de comunicação. Desconsidera, também, a influência do mercado na reconfiguração dos grupos de mídia e na definição dos conteúdos dirigidos para a audiência.

Essas alterações do conceito de Comunicação Pública foram visíveis na Europa, com o desenvolvimento do rádio nos anos 20 e 30 e, mais tarde, no pós-guerra, com a televisão.

Segundo Serrano ${ }^{1}$ (2006), a intervenção do Estado nos meios de comunicação sempre foi considerada como limitante da liberdade de expressão e, ao mesmo tempo, como defensora do pluralismo desta mesma liberdade.

Ao longo do tempo, a imprensa foi adquirindo certa independência na luta contra o controle do Estado, sendo a publicidade comercial uma forma encontrada para diminuir a necessidade de subsídios oficiais. Desta maneira, a independência crescente dos meios de comunicação acabou por permitir que exercessem a função de órgãos de serviço público, aumentando sua credibilidade junto à audiência, e, pela vigilância, tornando o governo mais responsável.

Nesse contexto, surge em 1920, na Inglaterra, uma corporação pública, a British Broadcasting Company (BBC), com uma reputação de serviço de utilidade pública,

1 Disponível em: <http://www.bocc.ubi.pt/pag/SERRANO-estrela-espaco-publico-estado.pdf.>. Acesso em: 20 mai 2006). 
numa sociedade marcada pelo descontentamento do embate entre o mercado e as forças políticas. Este modelo não visava ao lucro ou ao controle político, mas, sim, a assegurar a qualidade dos programas aos espectadores. "Dentro das definições deste serviço público, existiu uma permanência de termos como: interesse social, qualidade, bem comum e equilíbrio, com objetivos educativos e informacionais para toda a sociedade sem distinção" (SERRANO, 2006).

No entanto, a lógica do mercado voltada para a satisfação da audiência, a preocupação com a cidadania, a exigência da massificação dos conteúdos, e o apelo ao consumismo caem numa contradição não resolvida.

Assim, a pressão econômica começou a se mostrar mais limitante do pluralismo do que a própria censura política. As práticas do mercado acabaram substituindo a repressão legal por conformidade com a ordem estabelecida. Com o crescimento da publicidade nas mídias, a independência em vista dos interesses políticos foi substituída pela dependência diante dos anunciantes.

Em 1997, Bland, presidente da BBC, aponta as prioridades a serem cumpridas pela entidade pública, que chama de quatro pilares do serviço público, sendo eles

"a qualidade, a diversidade, a inovação, a diferenciação e a reflexão quanto à cultura nacional. Sob tal ótica, a utilidade pública abarca não só a difusão da informação com imparcialidade e independência editorial, como também servir de modelo para as demais radiodifusoras". (SERRANO, 2006)

Estas propostas não foram seguidas por Birt, diretor-geral da BBC, que preferiu atender aos interesses da audiência, buscando conhecer e atender a suas preferências. Segundo relatório publicado pela União Européia em 1996,

"o serviço público de radiodifusão deve seguir cinco princípios básicos: caráter nacional, satisfação de diferentes necessidades dos grupos sociais, monopólio com controle da autoridade pública, acessibilidade, natureza não comercial e financiamento por fundos públicos; privilegiando a vertente cultural, distanciando-se do discurso político". (SERRANO, 2006)

Tais modelos foram seguidos na Espanha com a TVE, e em Portugal. Já a Rádio France adaptou o modelo proposto pela UE, destinado, ao mesmo tempo, a integrar e a fortalecer a cidadania e atender ao gosto do público, juntamente com a proposta de preservar os valores da universalidade, continuidade, neutralidade e acessibilidade.

Segundo Dines (2005), as perspectivas para a PBS (Public Broadcasting System) americana na atualidade não são animadoras. Sua receita compõe-se de contribuições do público e do Estado, em partes iguais. No entanto, o monolitismo político-religioso 
(hoje majoritário nos EUA depois da reeleição do presidente Bush) faz prever uma queda nas doações e, por conseguinte, uma queda nas dotações.

No Brasil, existem duas redes consideradas públicas: a TV Cultura, do Estado de São Paulo, e a TV Educativa (TVE), do governo federal. Estas redes esforçam-se para informar com isenção, concentrando-se em atender os objetivos contidos no Manual de Jornalismo Público e nos respectivos nomes - cultura e educação. No entanto, enfrentam dificuldades financeiras e, segundo Dines, "são públicas na atitude, mas estatais no plano real" (2005).

Embora o conceito de cidadania global da informação tenha surgido das novas tecnologias e de seus impactos sociais, a presença dos conglomerados de mídia, o fluxo assimétrico da produção dos conteúdos e, mais recentemente, a convergência midiática têm tornado mais desigual a universalidade do acesso.

Sobre este aspecto, um documento do Conselho da Europa, dirigido por Bangeman (1996), traçou um programa de ação para a nova era da informação. Nele são propostos programas de e-learning, disseminação do acesso on-line para toda a população e redes de administração pública. O documento deixa claro que o financiamento desta tecnologia cabe ao setor privado e à força do mercado, cabendo ao setor público desenvolver aplicações nas áreas de sua responsabilidade.

Uma outra visão da Comunicação Pública, ainda normativa, chama a atenção para outros aspectos - além da perspectiva de serviço público à disposição da cidadania e do interesse público. Dines observa a evolução das expressões usadas para nomear a comunicação: "Diante do extraordinário desenvolvimento do rádio nos anos 1920 e 1930 e da televisão no pós-guerra, consagrou-se a expressão 'comunicação de massa', substituída nos anos 1950-60 por outra, políticamente correta - 'comunicação social'”' (DINES, 2005).

No entanto, o afastamento da noção de comunicação social nos meios de comunicação não deve ser encarado, em si, como uma perda de liberdade política. Isto, segundo Libois (2002), se a Comunicação Pública for considerada em seu aspecto normativo e, portanto, distinta da comunicação midiática.

A entrada da mídia no mercado, onde a informação é tratada como produto, não significou necessariamente a perda de liberdade política. É preciso considerar o pluralismo interno, não na dimensão do simples direito à recepção de informação, mas, sim, na necessidade de variedade de estilos, gêneros, opiniões e visões de mundo.

A determinação do conteúdo da Comunicação Pública é orientada pelo ideal normativo das referências convencionais, tais como: o interesse público, o direito à informação, a busca da verdade e da responsabilidade social pelos meios de comunicação de

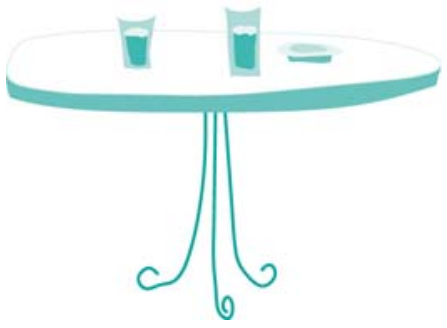


massa; isto leva a refletir sobre as práticas profissionais dos comunicadores envolvidos e os princípios normativos que lhe servem de orientação.

Entre as ações normativas, algumas se referem ao direito de resposta da audiência, outras a tentativas de estabelecer alguma forma de censura prévia pelo Estado, ou a uma posição editorial do veículo, ou ainda às ameaças das quais as mídias são vítimas freqüentes (visando sua subordinação a grupos de interesse político ou financeiro, uma ação política de marketing e/ ou Relações Públicas desvirtuadas).

O esforço normativo do conceito de Comunicação Pública remete, segundo Libois (2002), à hipótese de uma deformação estrutural da comunicação, localizada em três fontes: a política, a econômica e a midiática.

A orientação básica do conceito de Comunicação Pública é prioritariamente de ordem democrática, referente ao senso comum político, e em associação direta com normas herdadas da visão liberal - em estreita relação com o Estado. Secundariamente, está em conformidade com os valores relacionados à comunicação como instrumento e meio independente do Estado, sendo, como meio, direcionado à vertente pública, à cultura nacional, à vertente privada, e à econômica (pelo princípio do mercado). E, por último, nas palavras de Libois (2002, p.36),

"o princípio da dimensão de crítica interna à própria comunicação, possibilitando a visão da liberdade de opinião como liberdade de formular uma opinião segundo os interesses do grupo representado. Neste sentido, o pluralismo deve visar não somente à variedade de opiniões e de pontos de vista, mas à igualdade de questões e temas tratados". (2002, p.36)

O princípio da dimensão crítica dos meios de comunicação permite identificar uma dificuldade pouco explorada nas discussões da Comunicação Pública: a função da programação da mídia que, com o interesse voltado para a resposta da audiência, distancia-se da prestação pública de contas (accountability), uma vez que o agendamento e a formatação das questões de interesse público não são explicados e justificados para a audiência.

\section{Comunicação Pública e processo de Comunicação Política}

A reflexão sobre o contexto histórico e normativo do conceito de Comunicação Pública, no Brasil e na Europa, nos leva ao impasse da proeminência do mercado para reorientar os objetivos dos grupos de mídia, responsável pelo deslocamento progressivo do pólo público-cidadão ao pólo público-consumidor.

Nesta nova condição, a análise do locus da Comunicação Pública também se desloca 
da mídia, como produtora dos conteúdos interesse público, para o campo da Comunicação Política, espaço interdisciplinar que tem se dedicado a estudos nos domínios do exercício do poder. E por que a Comunicação Política?

Como já foi indicado, os estudos da Comunicação Pública estiveram relacionados, até o final do século XX, com a regulamentação e o controle da mídia, no sentido de submetê-la aos padrões de interesse público. Por outro lado, a pesquisa da Comunicação Política, comprometida com o nascimento da Teoria da Comunicação, especialmente em Lazarsfeld, Lewin, Hovland e Laswell, abriu inúmeras perspectivas de estudo do fenômeno, contemplando várias áreas da ciência: Sociologia, Ciência Política, Lingüística, Administração Pública, História, entre outras.

Um outro aspecto a considerar é que o campo de interesse neste artigo não é retomar a dimensão técnica da persuasão, que caracteriza inúmeras pesquisas (desde a propaganda política até o marketing político), mas é voltar-se para a dimensão política que tem sido usada nos estudos da Comunicação Política.

Salientando a legitimidade do campo por uma reconhecida tradição de pesquisas, torna-se necessário refletir, agora, sobre o processo da Comunicação Política, suas dimensões e concepções, em busca da compreensão da inserção da Comunicação Pública neste contexto. Por considerar a comunicação governamental como uma das formas de Comunicação Pública, o texto busca verificar as possíveis articulações entre Comunicação Política e Comunicação Pública.

Gerstlé (2005) propõe uma abordagem do processo de Comunicação Política partindo de três concepções: a instrumental, a ecumênica e a competitiva; às quais acrescento a deliberativa, como possibilidade de indicar o lugar e as finalidades que envolvem os agentes sociais na Comunicação Pública. Essas abordagens não são excludentes e nem são pensadas de modo evolutivo.

A concepção instrumental coloca a Comunicação Política como um conjunto de técnicas usadas por políticos e governantes para seduzir e manipular a opinião pública. Neste eixo também podem ser incluídas a comunicação governamental e sua estratégia recorrente de abordar a sociedade pela via da propaganda ideológica e/ou institucional; tais fronteiras nem sempre são fáceis de delimitar.

No eixo instrumental também pode ser incluída a função educativa e cultural, preconizada pela noção de difusão pública, até a metade do século XX, por sua natureza de regulamentação e controle; e também podem se consideradas instrumentais as experiências históricas do nazi-fascismo na Europa, os regimes populistas e, mais tarde, as ditaduras militares na América Latina, como apontado por Matos (2004).

O final do período militar colocou em evidência o potencial de organização da socie- 


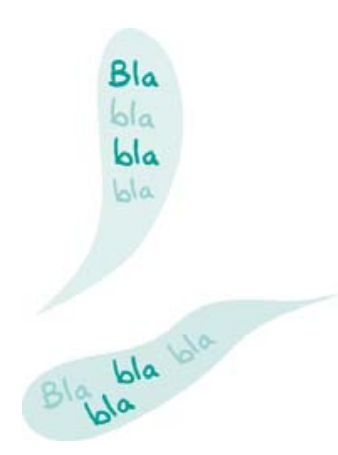

COMUNICAÇÃO POLÍTICA E COMUNICAÇÃO PÚBLICA • HELOIZA HELENA GOMES DE MATOS

dade e as ações das comunidades de base, o fortalecimento do movimento sindical, a criação do Partido dos Trabalhadores e, ainda, a grande mobilização do movimento das diretas; até mesmo a atuação dos conselhos de regulação de direitos (de minorias) passou a evidenciar as condições para a emergência de uma nova Comunicação Pública.

No entanto, o marketing político emerge com suas estratégias de buscar, no consumidor real e/ ou potencial do mercado político-eleitoral, as expectativas e desejos, imprimindo, assim, na visão instrumental, os atributos e potencialidades esperados nos candidatos aos cargos eletivos e nos governantes em atuação.

A concepção ecumênica de Comunicação Política é entendida como processo interativo, incluindo a troca de informações entre atores políticos, a mídia e o público. Configura-se muito próxima de uma representação sistêmica, característica do funcionalismo. O que conta é a circulação de informações entre atores envolvidos, independentemente das forças sociais e da cultura política que permeiam o ambiente.

Há nesta concepção uma indeterminação relacionada com a natureza da informação transmitida pelos agentes políticos. Além da questão legal e convencional que envolve a mensagem e o contexto da fala, outros bens simbólicos entram em disputa no espaço público político: imagens, representações e preferências.

Desta forma, a interpretação desta modalidade de Comunicação Política é mais do que compreender a dinâmica do intercâmbio entre os atores. Gerstlé (2005) exemplifica que um pronunciamento do Presidente e um movimento grevista, além do intercâmbio de mensagens, não podem prescindir da análise dos impactos da mesma mensagem em diferentes atores e segmentos do mercado político. É nessa condição que podem ser articuladas a Comunicação Política e a Pública.

Assim, é necessário estabelecer distinções entre os canais institucionais, compreendidos pelo parlamento e a administração pública, os canais organizacionais, incluindo partidos e movimentos e forças organizadas, os canais midiáticos, com a participação das mídias de massa e aquelas presentes no espaço da Internet, e os canais interpessoais, constituídos pelos grupos sociais e as relações entre indivíduos.

Embora a multiplicação e variedade de fontes tenham contribuído para reforçar as disputas no mercado de informação e comunicação, ficam também abertas as possibilidades de produção e disseminação de mensagens de natureza pública e o envolvimento da sociedade em todas as etapas da Comunicação Pública.

Wolton (1989:31) considera a Comunicação Política como o "espaço no qual se trocam discursos contraditórios entre os três atores que têm legitimidade para se expressar publicamente sobre a política: políticos, jornalistas e OP - via pesquisas". Tal conceito é duramente criticado por Gerstlé (2005), pela sua natureza "elitista" e por 
desconsiderar a legitimidade de outras vozes não institucionalizadas ou que estejam fora do controle da mídia e das pesquisas de opinião.

Abre-se novamente, por meio do conceito de Comunicação Política, a possibilidade de agregar uma nova reflexão pela busca do entendimento da Comunicação Pública: que outras vozes estariam autorizadas além daquelas apontadas por Wolton? O debate público é condição essencial para a tomada de decisão política? Como ignorar as especificidades da mídia e das novas sociabilidades decorrentes, por exemplo, das tecnologias da comunicação e da informação? Não temos todas as respostas. Este artigo visa a, exatamente, provocar o debate.

A abordagem competitiva da Comunicação Política se apóia no embate para influenciar e controlar, pela mídia, as percepções públicas dos acontecimentos políticos que estão em jogo. Passa-se, assim, da troca indeterminada de mensagens para a competição explícita pelo controle das representações políticas. Nesta interação, a mídia entra em cena, tendo como papel central os aspectos cognitivos e simbólicos.

Baseado na premissa de Nimmo (1970), Blumler (1990) afirma que o impacto da mídia tem sido maior na cognição do que nas atitudes, e que estas seriam o resultado de um aprendizado gradual por meio da repetição e práticas de novas maneiras de ver o mundo.

No entanto, a contribuição mais significativa de Blumler está na afirmação de que "a mídia está sendo considerada dentro e não acima das forças do poder, sujeita a outros poderes. Para determinar que versões da realidade são aceitáveis numa base mais ampla, para moldar os valores da sociedade" (BLUMLER, 1990, p. 114). O autor afirma ainda que o processo de Comunicação Política moderna poderia ser comparado com a força quase irresistível de um ímã, obrigando todos aqueles que entram no seu campo de ação a se adaptarem. Ou seja, o processo não só altera a recepção das mensagens, os temas e os termos usados no embate político, como também é capaz de influir ou mudar as perspectivas e escolhas dos cidadãos.

Diante do exposto, é preciso considerar que a abordagem competitiva (que ressalta a centralidade da mídia e o controle das representações políticas) não exclui a cognição na formação da opinião e a participação do cidadão no debate público.

No entanto, é a concepção deliberativa que viabiliza a proposta de Blumler, incluindo a participação no debate num espaço público ampliado: a mídia de massa não deixa de ser considerada no processo de formação das opiniões políticas; no entanto, segundo a teoria da deliberação, é no debate coletivo que se criam as condições para uma democracia ampliada, quando a participação dos cidadãos (independentemente dos critérios de gênero, nacionalidade, raça, religião e idade) permite a formação de um autêntico espaço público. Segundo Cohen (1990), a noção de democracia deliberativa tem origem num ideal intuitivo de associação democrática, na qual a justificativa das condições associativas tem origem numa argumentação pública de cidadãos iguais. 
As concepções deliberativas da democracia baseiam-se no princípio de que "as decisões afetando o bem-estar de uma coletividade devem ser o resultado de um procedimento de deliberação livre e razoável entre cidadãos considerados iguais moral e politicamente" (BENHABIB, apud MAIA, 2003, p. 69). Neste sentido, o "interesse comum" aparece como resultado de um processo de deliberação coletiva e é condição necessária para a legitimidade do exercício do poder e da racionalidade na tomada de decisões políticas - não apenas do voto, durante o processo eleitoral, mas de forma contínua e ampliada, ou seja, das decisões que afetam a vida dos atores sociais.

"Os ideais do modelo deliberativo de democracia parecem 'viáveis' apenas em pequenas escalas espaciais e temporais. No entanto, diversos autores têm refutado os pressupostos básicos do elitismo democrático de que as formas mais complexas de administração podem prescindir da participação ativa e argumentativa por parte do público mais amplo. Esses autores sustentam que é possivel reconhecer a complexidade dos problemas na sociedade contemporânea e o pluralismo dos interesses envolvidos, e, ainda assim, defender os ideais democráticos de autonomia e soberania dos cidadãos". (BENHABIB, apud MAIA, 2003, p. 69)

As transformações sociais decorrentes, entre outros fatores, da nova economia, tiveram também impactos significativos nas formas de intervenção da sociedade organizada - movimentos sociais, ONGs e grupos sociais - com uma pluralidade de interesses e demandas.

Essas demandas, além de reduzir o nível de tensão entre os interesses de públicos diversificados, passaram a ser consideradas, pelas instituições e corporações, como potencial para agregar valor à marca, o que pode ser observado pelo crescimento da prática de programas de responsabilidade social - seja com caráter mercadológico, institucional, financeiro ou como resposta às ações reivindicatórias dos grupos de interesse da causa em questão.

Estas questões, mesmo tendo sido resultado de debates segmentados, ao longo do tempo, pelo trabalho das assessorias de comunicação organizacional, buscaram e obtiveram visibilidade na mídia, com a vinculação de anúncios institucionais, divulgação de balanços - financeiros e sociais - como parte da exigência dos stakeholders e, para abranger as novas pautas, deu-se a criação de editorias e publicações especializadas no terceiro setor e temas relacionados com a responsabilidade social. E, ainda, apoiadas pela legislação que regula os investimentos na cultura, as empresas, privadas e estatais, passaram a investir pesadamente em programas esportivos e culturais, assumindo funções antes exclusivas do Estado.

É nesse contexto que são criadas as condições para o ressurgimento do conceito de Comunicação Pública, seja no formato de jornalismo de serviço (principalmente no rádio ou programas de TV locais e ou regionais) ou em redes educativas e/ ou culturais, na proposta de jornalismo público. 
O auge desse momento se dá no Brasil em 2002, na eleição de um Presidente da República com uma história política e pessoal sensível e próxima a essas novas demandas sociais. A referência a essa nova condição não é uma proposta de análise da comunicação no governo Lula; antes, serve apenas para mencionar que uma concepção republicana do Estado encaminha o debate para consolidar a visão de Comunicação Pública, substituindo a antiga fórmula de propaganda governamental. Só para sintetizar a observação, o que se deu foi uma confirmação da publicidade governamental como abordagem instrumental privilegiada para a comunicação do governo, apartada da política social proposta desde a campanha eleitoral. E esta mesma publicidade passa a ser mencionada como prática de Comunicação Pública.

E, como hipótese a ser avaliada em futuras pesquisas, ocorre um retrocesso da participação da sociedade em projetos sociais, substituída por programas outros em que o governo oferece e o cidadão recebe porque de fato é carente, mas em que participa muito pouco do processo social e comunicativo. Ou seja, a sociedade fala, o governo escuta e atende, segundo critérios de prioridade não muito claros. No entanto, novamente, temos o nome e não a coisa. O que o governo brasileiro mostra atualmente pode ser visto como comunicação governamental, marketing público, político ou e-governo, mas com certeza não é comunicação pública. Esta depende de outras especificidades não unicamente presentes nas políticas públicas de comunicação. Estão também inseridas na qualidade das interações nas redes sociais do capital social delas decorrentes.

\section{Perspectivas para a viabilização do conceito de Comunicação Pública}

O estudo indica que a Comunicação Política vai além da comunicação governamental, comunicação eleitoral ou marketing político. Por outro lado, a Comunicação Pública se articula com a Comunicação Política na esfera pública, como local de interação social de todos os agentes e interesses envolvidos. Nesta esfera, transitam recursos humanos (cidadãos, políticos, eleitores), físicos (suporte da comunicação massiva, tecnologias interativas e convergentes), econômicos (capital, ativos em geral), comunicacionais (discursos, debates, diálogos estruturados dentro e fora das mídias massivas e recursos interativos). A questão central é saber, nesta esfera de relações, o que se busca e o que é obtido: o poder está sempre em jogo, mas só os temas e interesses comuns dizem respeito à Comunicação Pública.

Ironicamente, quando o estudo da Comunicação Pública parece resumido à questão única da mídia, é preciso voltar ao estudo da Comunicação Política para fazer avançar o campo da Comunicação Pública. Dos vários conceitos propostos sobre Comunicação Política que podem ajudar no entendimento da Comunicação Pública, reafirmo que o poder é a arena comum nos dois conceitos, embora os interesses envolvidos nem sempre convergem. Das dimensões propostas para a análise da Comunicação Política por Gerstlé (2005) e Maia (2002), a visão deliberativa aponta o 
debate coletivo como condição necessária para a legitimidade do exercício do poder e da racionalidade na tomada de decisões políticas - não apenas restritas ao voto, durante o processo eleitoral, mas, de forma contínua e ampliada, das decisões que afetam a vida dos atores sociais.

Mas vale lembrar: recorrer à Comunicação Política para fazer avançar o estudo da Comunicação Pública não significa submeter esta àquela. Pelo contrário: há indícios neste estudo que é a Comunicação Pública que contém a Comunicação Política; não o inverso.

Embora a questão da tecnologia não tenha sido tratada em profundidade, reitero que os avanços das tecnologias da comunicação e da informação têm sido determinantes para a busca de novas formas de accountability nas relações entre o Estado e a sociedade, e ainda como recurso interativo para o conhecimento e debate das questões de interesse público.

Concluindo, indico pistas para os estudos das redes sociais e comunicativas como determinantes para a formação do Capital Social. O tema tem sido tratado do ponto de vista sociológico, econômico e, mais recentemente, pela ótica da comunicação, como se vê em Bordieu e Coleman (1989), Putnam (1993) e Gomes (2006).

Considero que o aprofundamento do conceito de Capital Social pode oferecer aberturas para a compreensão da Comunicação Pública, não como ação isolada do governo, das organizações ou da mídia, mas como resultado da força das redes sociais; nele, a confiança e a continuidade das interações entre os agentes sociais pode oferecer a possibilidade de uma interação contínua e rica entre o Estado e a sociedade. Esta via permitiria à Comunicação Pública avançar por um caminho próprio, sem necessidade de recorrer somente aos estudos de Comunicação Política para sair de seu impasse. Enfim, os estudos sobre o Capital Social têm muito a aportar ao estudo da Comunicação Pública, mesmo na vertente do impacto da tecnologia sobre seus fenômenos.

\section{Bibliografia}

BOURDIEU P.; COLEMANN J. (dir.). Social Theory for a changing society. New York: Russel Sage Foundation, 1991.

BLUMLER, J.G.. Elections, media and modern publicity process. In: FERGUSON, M. (ed.). Public communication - the new imperatives: future, directions for media research. London: Sage, 1990. p. 101-113. (tradução livre de Heloiza Matos para fins exclusivamente acadêmicos).

COHEN, J. S. Deliberation and a democracy legitimacy. In: HAMLIN, Alan; PETTIT, Philip (eds.). The good polity. Oxford: Blackwell, 1990. p. 12-34.

CONSEIL DE L'EUROPE. Public service broadcasting, cultural and educational dimensions. Paris: Unesco, 1996. 
COMUNICAÇÃO POLÍTICA E COMUNICAÇÃO PÚBLICA • HELOIZA HELENA GOMES DE MATOS

COSTA FILHO, Paulo Celestino. Jornalismo Público: por uma nova relação do jornalismo com os públicos. Monografia (Especialização em Gestão Estratégica em Comunicação Organizacional e Relações Públicas - Gestcorp) - Departamento de Relações Públicas, Propaganda e Turismo da Escola de Comunicações e Artes. São Paulo: Universidade de São Paulo, 2003.

DINES, Alberto. Conceitos de serviço público: media, estatais e privados. In: $6^{\circ}$ CONGRESSO INTERNACIONAL DE JORNALISMO DE LÍNGUA PORTUGUESA. Disponível em: <http//observatóriodeimprensa.ig.com.br>. Acesso em: 05 ago. 2005.

DUARTE, Jorge; VERAS, Lucia (org.). Glossário de comunicação pública. Brasília: Ed. Casa das Musas, 2006.

GERSTLÉ, Jacques. La communication politique. Paris: Armand Colin, 2005.

GOMES, Wilson. Toqueville não via TV: capital social, democracia e televisão em Robert Putnam. In: XV ${ }^{\circ}$ ENCONTRO DA COMPOS NA UNESP, GT n. 02 de Comunicação e Política. Bauru: Unesp, 2006.

LIBOIS, Boris. La communication publique: pour une philosophie politique des medias. Paris: L'Harmatan, 2002. (Tradução de Caia Fittipaldi para finalidade acadêmica).

MAIA, Rousiley Celi. 2002. Dos dilemas da visibilidade midiática para a deliberação pública. In: XI ENCONTRO DA COMPOS, GT de Comunicação e Política.

MARTINS, Luiz. (org.); BRANDÃO, Beth; MATOS, Heloiza. Algumas abordagens em comunicação pública. Brasília: Casa das Musas, 2003.

MATOS, Heloíza. Comunicação pública, democracia e cidadania: o caso do Legislativo. Revista Líbero. São Paulo: Faculdade Cásper Líbero, v. 2, n. 3-4, p. 32-37, 1999.

. Comunicação pública e comunicação global. Revista Líbero. São Paulo, Faculdade Cásper Líbero, v. 3, n. 6, p. $64-69,2000$.

Um discurso político oculto na comunicação institucional do governo Médici. Revista Communicare. São Paulo, Faculdade Cásper Líbero, v. 1, p. 54, 2004.

MATOS, Heloiza; NOBRE, Guilherme. Comunicação para uma gestão cidadã. Ceará: Escola de Formação de Governantes e Brasília, Ed. do Senado Federal, 2001.

OLIVEIRA, Maria José da Costa (org.). Comunicação pública. Campinas: Alínea, 2004.

PUTNAM, R. The proposperous community: social capital and public life. The American Prospect. v. 4, n. 13, p. 35-42, 1993.

SERRANO, Estrela. O espaço público e o papel do Estado na sociedade global da informação. Lisboa, 1998. Disponível em: <http://www.bocc.ubi.pt/pag/SERRANO-estrela-espaco-publico-estado.pdf>. Acesso em: 20 mai. 2006.

WOLTON, Dominique. La comunicación política: construcción de un modelo. In: FERRY, Jean Marc; WOLTON, D. (org.). El nuevo espacio publico. Barcelona: Gedisa, 1989.

ZEMOR, Pierre. La communication publique. 3. ed. Paris: Presse Universitaire, 2005. 